\title{
Effect of pellet and mash feeding on the performance of growing rabbit
}

\section{MZ Rahman ${ }^{1}$, A Reza ${ }^{1}$, MA Siddiki ${ }^{1}$, MI Hossain ${ }^{2}$, M Asaduzzaman $^{2}$ MM Rahman ${ }^{2}$}

${ }^{1}$ Upazila Livestock Officer, Department of Livestock Services, Dhaka, Bangladesh; ${ }^{1}$ Professor, Department of Animal Nutrition, BAU, Mymensingh, Bangladesh; ${ }^{1}$ Scientific Officer, Department of Livestock Services, Dhaka, Bangladesh; ${ }^{2}$ Department of Livestock Services, Dhaka, Bangladesh; ${ }^{2}$ Deputy Project Manager, Nobokoli Project, World Vision, Bangladesh

\begin{abstract}
The present study was undertaken to know the effect of pellet and mash feeding on nutrient digestibility, growth performance and carcass weight of growing rabbits. For this purpose fifteen crossbred NewZealand white rabbit were selected for conducting the experiment. The Average ages of these experimental rabbits were 1.5 to 2.0 months. All the rabbits were housed in Quonset style cages. Animals were distributed to mash $\left(T_{1}\right)$, pellet $\left(T_{2}\right)$ and mixture of pellet and mash $\left(T_{3}\right)$ groups equally with five animals in each group. All the animals were supplied ad libitum green grass. The experiment shows that highest body weight was found from pelleted group. Growth rate of different dietary treatment differ significantly $(p<0.05)$. FCR of different dietary groups did not differ significantly. Carcass weight and dressing yield of rabbits did not differ significantly, but dressing yield was highest for pelleted group. So the study reveal that, feeding of pelleted diet resulted in higher growth rate, growth velocity, dressing yield, better feed conversion efficiency compared to mash and pellet with mash.
\end{abstract}

Key words: Rabbit, pellet, productive performance

Bangladesh Animal Husbandry Association. All rights reserved. Bang. J. Anim. Sci. 2015. 44 (2): 100-105

\section{Introduction}

Rabbit (Oryctolagus cuniculus) is a small nonruminant animal which may be recommended as an alternative source for meat production. Cattle rearing require more money and more space, but less money and/ or less space are involved in rabbit rearing. The domestic rabbit is considered as viable livestock species (Cheeke, 1979) and is raised for several purposes including meat and fur production, laboratory animals, for show and as pets (Cheek, 1986a). Rabbit have number of characteristics such as small body size, short generation interval (gestation length 28-32 days), high productive potential ( 4 or 5 litters per year with an average of 5.8 young per year), rapid growth rate and genetic diversity (Cheeke, 1986b). Ultimately rabbit is enabling to attract the attention of farmer as well as the private industry. The environments, climatic condition, religious issue, social status of Bangladesh are favorable to rabbit production and these are easy to handle and live on easily available grass. It is reared easily by village woman and children. Moreover, rabbit meat is high quality, because it is high protein content and low in fat and cholesterol (Jones, 1990, Handa et al., 1995). Rabbit is a monogastric animal but can utilize cellulose content of feed for the presence of caecum with the enzyme of cellulose. Cheeke (1986a) indicated that rabbits are primarily herbivores and can be successfully raised on diets that are low in grain and high in roughage. The ability of rabbit to convert roughage into meat efficiently will be of great help for Bangladesh where animal feed shortage is an acute problem. It has been reported that growing rabbits can be maintained satisfactorily on diets consisting of 100-200g green roughage and 40-60g concentrate mixtures preferably in the form of pellet (Ranjhan 1980) for optimum production and about 4 months are required to produce $2 \mathrm{~kg}$ market rabbit under subsistence condition (NRC 1991). Howlider and Rose (1992) found that pelleting increased feed conversion by $5.9 \%$ for rabbit, less feed wastage is possible in pellet feeding comparing mash feeding. So pellet feeding to rabbit may cause similar effect as poultry which is also a monogastric animal. Therefore, comparative study on pellet and mash 


\section{Rabbit production in Bangladesh}

feeding is necessary for obtaining new information for rabbit production. The present study was undertaken to know the effect of pellet and mash feeding on nutrient digestibility, growth performance and carcass weight of growing rabbits.

\section{Materials and Methods}

\section{Location and Time}

A total of fifteen crossbred New Zealand white rabbit about 1.5 to 2.0 months of age were selected to conduct the present study and the study was carried out at the animal nutrition field laboratory, Bangladesh Agricultural University, Mymensingh. Chemical analysis of mash and pellet feed was done in the laboratory of Department of Animal Nutrition, Bangladesh Agricultural University, Mymensingh. The study was done during the period of April 24 to June 26, 2003.

\section{Experimental design and dietary treatment}

Animals were randomly distributed to three treatment groups having five animals in each group. The treatment groups were Treatment$1\left(T_{1}\right)$ concentrate feed of mash form, Treatment$2\left(\mathrm{~T}_{2}\right)$ concentrate feed of pellet form and Treatment- $3\left(\mathrm{~T}_{3}\right)$ concentrate feed of $50 \%$ mash form and $50 \%$ pellet form. All the animals were supplied ad libitum green grass and fresh water was made available to the rabbits at all time.

\section{Preparation of concentrate mixture}

All the ingredients were mixed properly but only oil was added to the mixed feed just prior to use for the prevention of rancidity of fat and feed was safe for experimental animal where $3.5 \%$ oil was mixed. The composition of mash feed was given in Table 1 and the selected pellet was purchased from Quality Feed Ltd. which having 2800-2900 $\mathrm{kcal} \mathrm{ME} / \mathrm{kg}$ and $20 \%$ crude protein.

\section{Feeding and management of rabbits}

All animals were housed in individual steel cage pans having well lighted and well ventilated. Sanitary measure was taken for prevention of diseases. The rabbits were reared in three groups. Ad libitum supply of green grass was common to all three groups. They differ from concentrate supply. From the very beginning of the experiment up to 16 days, roughage and $70 \mathrm{~g}$ concentrate was supplied to each rabbit but for rest of the experimental period, $80 \mathrm{~g}$ of concentrate was supplied to each animal in the form of mash $\left(T_{1}\right)$, pellet $T_{2}$ ) and pellet and mash $\left(\mathrm{T}_{3}\right)$.

\section{Measurements of feed intake and live weight}

The leftover of roughage and concentrate feed was measured daily in the morning prior to supply of feed and left over from supplied amount of feed was deducted for obtaining the amount of feed intake per day. Prior to start of the experiment live weight of each animal was measured and recorded. Live weight was taken once in a week in a particular day in the morning at 6.30 A.M. before feeding and the weight gain was calculated by subtracting the initial weight from the final weight and daily weight gain was calculated.

Table 1. Composition of mash feed given to growing rabbits

\begin{tabular}{|c|c|c|c|c|c|}
\hline Ingredients & $\begin{array}{l}\text { Amount of } \\
\text { fresh feed } \\
(\mathrm{kg})\end{array}$ & $\begin{array}{c}\text { DM content } \\
(\mathrm{kg})\end{array}$ & $\begin{array}{l}\text { ME content } \\
\text { (Kcal) }\end{array}$ & $\begin{array}{l}\text { ME content } \\
(\text { Kcal }) / \mathrm{kg}\end{array}$ & $\begin{array}{l}\text { Protein content } \\
\qquad(\mathrm{kg})\end{array}$ \\
\hline Maize & 34 & 30.39 & 101826.6 & 3350.66 & 2.88 \\
\hline Wheat & 15.5 & 13.95 & 43524 & 3120 & 1.53 \\
\hline Oil & 3.5 & 3.50 & 31150 & 8900 & 0 \\
\hline Wheat bran & 15 & 13.25 & 17218.5 & 1299.50 & 1.92 \\
\hline Til oil cake & 11 & 9.97 & 18935.4 & 1899.24 & 3.10 \\
\hline Soyabean meal & 20.5 & 18.39 & 38615.85 & 2099.83 & 7.36 \\
\hline Salt & 0.50 & 0.45 & - & - & - \\
\hline Total nutrient & 100 & 89.70 & 251270.35 & $251270 / 89.7=2801$ & 16.79 \\
\hline
\end{tabular}

Amount of Nutrient $2800 \mathrm{Kcal}$ ME/kg DM, CP=19\% 


\section{FCR and average daily gain}

Feed conversion ratio (FCR) and average daily gain was calculated as following formula

$$
\text { FCR }=\text { Daily DM intake }(g)
$$

$A D G=$ (Final live weight- Initial live weight)/Total days of study

\section{Growth velocity (GV)}

The growth velocity was calculated in a given period of time ( 8 weeks) as follows

$\mathrm{GV}=(\mathrm{FW}-\mathrm{IW}) / \mathrm{IW}$

Where, $\mathrm{FW}=$ Final body weight, I $\mathrm{W}=$ Initial body weight

\section{Measurement of carcass yield}

At the end of experiment, two rabbits from each treatment were randomly selected. They were weighted and slaughtered un-fasted for the measurement of carcass yield, dressing percentage, organ weight, blood, skin, shank, head, trachea, lung, kidney, whole digestive tract and carcass weight were recorded.

\section{Digestibility trail}

Towards the end of the experiment a conventional digestibility trial was conducted for 7 days. At the end of collection period the sun dried faeces were mixed, together and then ground for chemical analysis. Feed and faeces samples were analyzed following the methods of AOAC (1984).

\section{Statistical analysis}

Collected data for every parameter were analyzed using MSTAT statistical programme to compute analysis of variance (ANOVA) for a completely randomized design; Duncan's Multiple Range Test (DMRT) was done to compare the treatment means for different parameters.

\section{Results and Discussion}

\section{Effect of pellet and mash feeding on rabbit growth}

\section{Live weight gain}

The growth performances of rabbits fed ad libitum green grass along with either pellet, mash or pellet and mash feed were presented in Table 2. The initial and final average live weights of rabbit were 665.00,650.00, 680.00g and $1366 \mathrm{~g}, 1650 \mathrm{~g}, 1504 \mathrm{~g}$ and body weight gain was $701.00,1000.00$ and $824.00 \mathrm{~g}$ for the $T_{1}$, $T_{2}$ and $T_{3}$ respectively. The results shown that the live weight gain on different treatment groups were significantly different $(P<0.05)$. Howlider and Rose (1992) observed that the total meat yield as a proportion of live weight, was not altered by sex or diet form. The pellet feed caused increase in the fatness compared with the mash feed given to monogastric broiler. Rabbit is a mono gastric animal, so it may be obtained similar result.

Table 2 Growth performances of rabbit by feeding pellet and mash

\begin{tabular}{lccccc}
\hline \multirow{2}{*}{ Parameters } & \multicolumn{5}{c}{ Treatments } \\
\cline { 2 - 6 } & $\mathrm{T}_{1}$ & $\mathrm{~T}_{2}$ & $\mathrm{~T}_{3}$ & $\mathrm{SED}$ & Significance level \\
\hline Initial body weight $(\mathrm{g})$ & 665.00 & 650.00 & 680.00 & 131.65 & $\mathrm{NS}$ \\
Final body weight $(\mathrm{g})$ & 1366.00 & 1650.00 & 1504.00 & 162.69 & $*$ \\
Total body weight gain (g) & $701.00^{\mathrm{b}}$ & $1000.00^{\mathrm{a}}$ & $824.00^{\mathrm{ab}}$ & 93.65 & $*$ \\
Growth rate (g/d) & $12.52^{\mathrm{b}}$ & $17.86^{\mathrm{a}}$ & $14.71^{\mathrm{ab}}$ & 1.67 & $*$ \\
Total dry matter intake (g) & 3617.37 & 4181.75 & 4286.56 & 295.23 & $\mathrm{NS}$ \\
Daily dry matter intake (g) & 64.60 & 74.67 & 76.43 & 5.27 & $\mathrm{NS}$ \\
Growth velocity & 1.12 & 1.76 & 1.29 & 0.35 & $\mathrm{NS}$ \\
FCR & 5.12 & 4.22 & 5.32 & 0.46 & $\mathrm{NS}$ \\
\hline
\end{tabular}

$a, b$, Mean value with different superscripts differ significantly $(p<0.05) ; T_{1}=$ Green grass + mash feed, $T_{2}=$ Green grass + pellet feed, $T_{3}=$ Green grass + $50 \%$ mash feed $+50 \%$ pellet feed 


\section{Growth rate}

Average daily growth rate was 12.52, 17.86, $14.71 \mathrm{~g}$ for the treatments of $T_{1}, T_{2}$ and $T_{3}$ respectively (Table 2 ) and differed significantly $(p<0.05)$, this was occurred may be due to supply of pelleted diet to the animal. Lindblad et al. (1955) observed an increase in rate of growth of monogastric, chicks fed pelleted rations without increased consumption of feed. The findings supported the present study. ElKerdaway et al., (1992) found that average daily body weight gain of rabbits was 24.9, 23.4, 21.9 and $22.1 \mathrm{~g}$, which is differ than the present study.

\section{Growth velocity}

The growth velocity of different dietary treatment groups did not differ significantly, but the highest growth velocity was recorded $1.76 \mathrm{~g}$ for diet $\mathrm{T}_{2}$, followed by $\mathrm{T}_{1} \quad(1.12 \mathrm{~g})$ and $\mathrm{T}_{3} \quad(1.29 \mathrm{~g})$ respectively.

\section{FCR}

The average FCR of among the diet were 5.21, 4.22 and 5.32 respectively and the result did not differ significantly $(p>0.05)$ within the groups, but highest performance was found the pelleted group. Howlider and Rose (1992), Ruiz Feria and Lukefahr (1998), Bielanski et al.(1998), Sawal et al. (1995) also found that pelleting increased feed conversion.

\section{Daily and total dry matter intake (g)}

Average daily and total dry matter intake (up to 56 days) was $64.60,74.67$ and $76.43 \mathrm{~g}$ and $3617.37,4181.75$ and $4286.56 \mathrm{~g}$ for treatments $T_{1}, T_{2}$ and $T_{3}$ respectively and the dietary treatments did not differ significantly $(p>0.05)$. Park et al., (1983) reported that Hubbard broilers of 9 weeks of age eat more pellets than mash. Rabbit is also monogastric animal so similar result may be obtained.
Effect of pellet, mash and mixture of pellet and mash feeding on carcass weight

The average carcass weight was $887.50,815.00$ and $760.00 \mathrm{~g}$ for treatments $T_{1}, T_{2}$ and $T_{3}$ groups respectively (Table-3) and no significant differences were $(p>0.05)$ found among the treatment groups. The dressing yield (\%) was $55.52,56.97$ and $56.80 \%$ of $\mathrm{T}_{1}, \mathrm{~T}_{2}$ and $\mathrm{T}_{3}$ group respectively and the result showed nonsignificant $(p>0.05)$.

\section{Digestibility}

The digestibility of proximate components of different diets is representing in Table- 4 . The results shown that digestibility of DM was highest in group $T_{1}$ followed by $T_{2}$ and $T_{3}$ respectively and $T_{1}$ significantly $(p<0.05)$ higher than that of other groups. But no significant different were found another two groups. The CP content of different dietary treatment groups were 81.23, 84.86 and $81.08 \%$ for $T_{1}, T_{2}$ and $T_{3}$ respectively which was significantly $(p<0.01)$ differed between both treatment groups. The CF content of among the different dietary treatment groups differed significantly $(p<0.05)$. The EE content of diet $T_{1}$ was significantly $(p<0.01)$ higher than that of other two groups. NFE digestibility of treatments $\mathrm{T}_{1}, \mathrm{~T}_{2}$ and $\mathrm{T}_{3}$ were 80.39, 76.96 and $70.82 \%$ respectively which was differed significantly $p<0.01$ ) among the treatment groups. The result agree with the result of Amber et al., (2002), Deshmukh and Pathak, (1995), Gupta et al., (1993) and Rao et al., (1987) they found similar findings of different proximate component digestibility of rabbit.

Table 3. Carcass weight and dressing yield of growing rabbit

\begin{tabular}{lccccc}
\hline \multirow{2}{*}{ Parameters } & \multicolumn{5}{c}{ Treatments } \\
\cline { 2 - 6 } & $\mathrm{T}_{1}$ & $\mathrm{~T}_{2}$ & $\mathrm{~T}_{3}$ & $\mathrm{SED}$ & Level of significance \\
\hline Carcass weight gain (g/whole period) & 887.50 & 815.00 & 760.00 & 62.57 & $\mathrm{NS}$ \\
Dressing yield $(\%)$ & 55.52 & 56.97 & 56.80 & 1.55 & NS \\
\hline
\end{tabular}

$\mathrm{T}_{1}=$ Green grass + mash feed, $\mathrm{T}_{2}=$ Green grass + pellet feed, $\mathrm{T}_{3}=$ Green grass $+50 \%$ mash feed $+50 \%$ pellet feed 
Table 4. Digestibility of different nutrient component

\begin{tabular}{lccccc}
\hline Parameters & \multicolumn{5}{c}{ Treatments } \\
\cline { 2 - 6 } Digestibility (\%) & T1 & T2 & T3 & SED & Level of significance \\
\hline DM & $77.09^{\mathrm{a}}$ & $72.84^{\mathrm{b}}$ & $70.42^{\mathrm{b}}$ & 1.24 & $* *$ \\
$\mathrm{CP}$ & $81.23^{\mathrm{b}}$ & $84.86^{\mathrm{a}}$ & $81.08^{\mathrm{c}}$ & 1.06 & $* *$ \\
$\mathrm{CF}$ & $44.85^{\mathrm{a}}$ & $46.46^{\mathrm{a}}$ & $37.58^{\mathrm{b}}$ & 3.35 & $*$ \\
EE & $88.50^{\mathrm{a}}$ & $72.23^{\mathrm{b}}$ & $58.87^{\mathrm{c}}$ & 1.65 & $* *$ \\
NFE & $80.39^{\mathrm{a}}$ & $76.96^{\mathrm{b}}$ & $70.82^{\mathrm{c}}$ & 1.38 & $* *$ \\
\hline
\end{tabular}

$a, b, c$, mean value with different superscripts differ significantly $(p<0.05)$ or $(p<0.001)$.

\section{Conclusion}

From the above discussion it may be concluded that feeding of pelleted diet resulted in higher growth rate, growth velocity, dressing yield, nutrient digestibility, and better feed conversion efficiency in growing rabbits compared to those of feeding mash or mixture of mash and pellet diet. Therefore, feeding of pelleted diet may be recommended.

\section{References}

AOAC (1984). Official Methods of Analysis (14 ${ }^{\text {th }}$ Ed.), Association of Official Analytical Chemists. Washington DC, USA.

Amber K, Gad SM, Adawy El (2002). Response of growing rabbits to high dietary levels of linseed meal, nutritional and physiological study. Egyptian Journal of Rabbit Science, 12: 115-132.

Bielanski P, Niedzwiadck S, Zajae J, Kowalska S (1998). Studies on the use of a polish probiotic in rabbit feeding. Rocznik, Naukowe- Zootechniki, 25: 123-132.

Cheeke PR (1986a). Nutrition and feeding of rabbits. In Livestock Feeds and Feeding Academic Press. San diego, California. P. 560-573.

Cheeke PR (1986b). Potentials of rabbit production in tropical and subtropical agricultural system, Journal of Animal Science, 63: 1581-1583.

Cheeke PR (1979). Production and nutrition of rabbits in tropical and subtropical agricultural production system, Nutrition Abstract Review, 61: P. 134.

Deshmukh SV, Pathak NN (1991). Effect of different dietary protein and energy levels on growth performance and nutrient utilization in New Zealand White rabbit,
Journal of Applied Rabbit Research, 14: 1824.

El-Kerdaway DMA, Rashwan AA, Ibrahim H, ElGendy KM (1992). Digestibility, growth performance, carcass traits and some physiological aspects of growing New Zealand White rabbits as affected by partial substation of concentrates with carrot tops hay, Egyptian J ournal of Rabbit Science, 2: 61-71.

Gupta HK, Yadav BPS, Gupta JJ, Bujarbaruah KM (1993). Utilization of leguminous roughages in rabbit rations, Indian Journal of Animal Science, 63: 481-483. Howlider MAR, Rose SP (1992). The response of growing male and female broiler chickens kept at different temperatures to dietary energy concentration and feed form, Animal Feed Science and Technology, 39: 71-78.

Handa MC, Sapra KL, Shingari BK (1995). Rabbits for meat production. Asian Livestock, 20: 99-100.

Jones ND (1990). The developing market for farm bred meat rabbit in Britain. Animal Production, 50: P. 66.

Lindblad GS, Aitkin JR, Husker WG (1995). Studies on the use of barley in broiler rations, Poultry Science, 34: P.1208.

NRC (1991). Nutrient Requirements of Domestic Animals, Number 9, Nutrient Requirements of Rabbis, Second Revised Ed. National Academy of Science National Research Council, Washington, DC.

Ranjhan SK (1980). Animal Nutrition in tropics. Vkas publishing house pvt. Ltd. Sabibabad, Ghaziabad, P. 335.

Rao KS, Reddy MR, Reddy GVN (1987). Utilization of unconventional roughages by the 


\section{Rabbit production in Bangladesh}

rabbits, Indian J ournal Animal Science, 57: 1324- 1328.

Ruiz-Feria-CA, Lukefahr SD (1998). Rabbit growth and feeding performance in southern. Evaluation of Dolichos lablab (lablab pursuers) and opuntia stricta as local forages and Agriculture and
Environment for international Development, 92: 5-19.

Sawal RK, Bhatia DR, Bhasin V (1995). Comparative performance of rabbits fed on pelleted complete feeds available in Grass. Indian Journal of Animal Nutrition, 12: 113-115. 